\title{
PAIN, PATHOS, AND PARANOIA: RESPONSES TO THE UNSTRUCTURED OB COURSE*
}

\author{
Dave Ulrich, The University of Michigan \\ and \\ Warner Woodworth, Brigham Young University
}

Much debate has occurred in our profession about the relative merits of teaching a structured versus unstructured organizational behavior course (Woodworth, 1979; Bowen, 1980; Wanous, 1981). We would argue that the approach one takes in teaching organizational behavior is based on a theory, often inexplicit, about students and the learning process. For several years we have been experimenting with a classroom approach that is relatively unstructured. The present article reviews student expectations, satisfaction and performance in an unstructured organizational behavior course and faculty response to the course.

\section{Structure vs. Unstructure}

The more structured organizational behavior course typically follows a tightly scheduled syllabus, routine and predictable lectures, and multi-choice exams at midterm and during finals week. The emphasis is on course content and answers which are in the texts and lectures. The role of the students consists largely of taking notes, becoming good technicians who follow detailed instructions.

In contrast to such an approach, an unstructured scenario in the organizational behavior course is quite different. It operates on the assumption that education is a process, not a selection of content material. The emphasis is on defining crucial questions, not memorizing answers. To be clear, we do not see such an approach as aimless meandering or a laissez-faire logic. Perhaps instead of unstructured learning, a better term would be self-structure. The general goal is

\footnotetext{
*The authors express appreciation to Wayne Brockbank for assistance in collecting data for this research.
}

that of creating ideas, frameworks for understanding the surrounding society.

Our intent in this paper is not to diminish the role of structured OB source, but to make a case for the unstructured approach as an alternative. Ultimately, our position is that both approaches to learning are legitimate, and that each allows students in academia to derive growth from the challenge that may occur in higher education.

We see several elements of the unstructured classroom as major dimensions in the facilitation of learning:

1. Ambiguity - Rather than reduction of equivocality, our bias is that uncertainty ought to be heightened, explored, and utilized in helping students come to grips with the challenges, choices, and contradictions of organizational life. Here, a clearcut syllabus may not only be artificial, but immoral in the sense that it implies a rationality and order to organizations that seldom exists.

2. Locus of Control - Instead of an externally motivated student dependence on the professor to guide all discussions, we see the need for an internalized level of interest in learning. Rather than simply following instruction, real learning occurs when the student participates in deciding what and how to learn. The unstructured environment is likely to elicit individual responsibility because the commitment is not to the class or teacher, but to one's self.

3. Conflict - A key aspect fostering independence is lack of conformity to traditional thinking and dogma. The effective teacher of unstructured OB must 
not only tolerate, but encourage, conflict. He or she must model a climate of debate - a process which unfreezes the student's sacred assumptions and forces examinations of alternatives never before taken seriously. Attacking, forcing hard questions, and challenging personal views is critical to achieving the kind of rigorous thinking and self-examination necessary to survive and prosper in organizations. The structured approach to learning often leads to converging, narrowing of vision, and agreed upon answers. What is needed is expanded, divergent thinking which will yield unique and creative perspectives.

4. Application - An essential dimension to learning OB is that of doing it. Instead of an abstract, intellectual discussion, we see a vital need to experience, try things out, mix text material with the outside world. Thus the student becomes the central datum of the course, not a book. Creating an environment in which students move from diagnosis and good analysis to action, implementation, and evaluation is useful in producing a learning experience which is not static and irrelevant. Linkages between OB and reality exist more in the student's mind if and when the student makes them. They do not ipso facto build an interface between the learner and the data.

\section{An Unstructured Classroom Approach}

To test student perceptions and performance in an unstructured learning environment, we studied the reactions of students in three courses on social organization. ${ }^{1}$ Each course covered issues which students would likely face in dealing with organizations ranging from future employers to university administrators to social clubs. During class time, we discussed topics and raised questions such as:
- Definitions of and ways of looking at organizations.

- Rise of bureaucracy.
- How does my perception of an organization affect my performance?

- What is the role of an an organization in my professional development?

- What is the role of bureaucracy?

- What are the advantages and/or disadvantages of bureaucracy?

- How do I manage my personal growth in a bureaucracy?
${ }^{1}$ The three courses were taught similarly. When we tested for different student reactions across the three courses, we found none to be significant.
- Individual vs. the system.

- How much of my individual freedom do I allocate to an organization?

- What is my zone of indifference?

- Socialization and dissent.

- Group dynamics.

- Organizational processes (e.g., communication, goal setting, problem solving).

- Organizational change.

- Ethics and values.

- What are the cues that $\mathbf{I}$ need to respond to in an organization?

- What are the limits of dissent within an organization?

- What role do groups play in organizations?

- How do I behave in groups?

- How do I recognize these processes so that I can manage them in an organization?

- What are my personal process skills?

- Authority, influence, power.

- What is my response to authority?

- What are resources which I can use and are used on me for influencing others?

- Under what conditions do organizations change?

- How do I as an individual either instigate change or deal with organizational change?

- What are my personal values?

- How do my personal values match with ethics in society and in organizations?

To present these and other topics, we incorporated lectures, discussions, cases, and experiential exercises. We relied heavily on current events to present many of the concepts. Prior to each class we suggested readings to students which would complement the class discussion.

The professor's role was less one-way lecture and more that of a resource, facilitator, and discussion leader. At the beginning of the course, we organized the class into groups and required that the groups engage in a learning project. Each group then assumed responsibility for defining and completing the assignment. In addition to group work, we made explicit that the responsibility for learning rested with the students. Each individual student was responsible to demonstrate his or her learning. Some of the learning projects undertaken included book critiques (e.g., leadership in Watership Down; symbolism in Shardik; individual freedom in The Fountainhead, 1984; power in The Betsy), logs of personal reactions to the course experiences, experimental studies (e.g., a survey of attitudes on campus about organizational behavior), literature reviews (e.g., on motivation, managing a boss), personal reflections (e.g., on values, career plans, etc.), 
and involvement in firms (e.g., examining group process in an executive committee). As professors, we encouraged and suggested alternative projects. We served as resources and facilitators for any studentinitiated project. Papers or projects were welcomed throughout the semester, read and returned with comments. At the end of the semester, we encouraged students to write and turn in a summary of their learnings in the course and other projects completed during the semester.

Applying this philosophy to the classroom has met with mixed results. From our experiences teaching the course, we have found that a distinct split among students emerges. The two groups are distinguished by their learning styles. One group quickly deals with the ambiguity, benefits from a range of learning experiences, and gains personal insights into social phenomena. In general, this group enjoys and does better in the course. Another group (often the majority) wants to learn facts about organizations and thus feels cheated by the course and the instructor's lack of direction. This group may retain some facts, but generally finds the class confusing and boring and leaves without having learned to deal with ambiguity in social systems.

In asking students how they reacted to the course, we were interested in distinguishing between the two groups and the learning which each group attained. From our experiences in the course, we felt that students with more maturity and experience (as measured by a maturity scale, age, months employed, and years in college), more achievement orientation (as measured by college grade point average (GPA)), and internal locus of control (we used a measure of internal locus of control which did not meet adequate reliability measures, see Table 1) would be both more satisfied with the course (as measured by a scale on course satisfaction) and learn more from the course (as measured by grades at the end of the course). We felt that if we could identify these two groups, we could forewarn the students who typically have more difficulty with the course as to the experiences they should expect.

\section{Results of the Study}

In analyzing the data we collected, we found mixed results about student attitude and performance in an unstructured course.

As expected, students perceived the course as unstructured. On a seven point scale, the average on "structure of the course as compared to other courses" was 1.8 , with only eight students seeing the course as structured as other courses (score of four or greater). These eight students were removed from subsequent analyses. Evidently, the lack of course outline, heightened ambiguity, conflict, and emphasis on experience were correctly perceived by students in the course.

To test our ideas about student attitude and performance, we created scales on maturity, satisfaction, and locus of control (McKelvey and Sekarin, 1977). These scales were tested for their consistency and reliability. The results of these tests are in Table 1. The satisfaction and maturity scales evolved as predicted, but the locus of control scale failed to meet minimum reliability requirements. This scale was not used in subsequent analyses.

Table 1

Scale Factor and Reliability

\begin{tabular}{|c|c|c|c|c|}
\hline & $\begin{array}{c}\text { Mean } \\
\text { Factor } \\
\text { Loading }\end{array}$ & $\begin{array}{c}H i \\
\text { Loading }\end{array}$ & $\begin{array}{c}\text { Lo } \\
\text { Loading }\end{array}$ & Reliability \\
\hline Satisfaction (9 items) & .70 & .85 & .43 & .90 \\
\hline Maturity ( 5 items) & .62 & .74 & .51 & .68 \\
\hline Locus of Control (5 items) & .39 & .52 & .30 & .33 \\
\hline \multicolumn{3}{|l|}{ Sample Satisfaction Items } & Mean & $S D$ \\
\hline \multicolumn{3}{|c|}{$\begin{array}{l}\text { How valuable do you feel this course will be } \\
\text { to you in future employment? }\end{array}$} & 4.3 & .75 \\
\hline \multicolumn{3}{|c|}{$\begin{array}{l}\text { How likely would you be to recommend this } \\
\text { course with this instructor to a good friend? }\end{array}$} & 4.5 & .89 \\
\hline \multicolumn{3}{|c|}{ How satisfied have you been with this course? } & 4.1 & 1.20 \\
\hline \multicolumn{3}{|c|}{$\begin{array}{l}\text { To what extent do you think this course will be } \\
\text { valuable to you in future nonwork activities? }\end{array}$} & 4.6 & .95 \\
\hline \multicolumn{5}{|l|}{ Sample Maturity Items } \\
\hline \multicolumn{3}{|l|}{$\begin{array}{l}\text { Generally, I like myself. } \\
\text { (disagree }=1 ; \text { agree }=7 \text { ) }\end{array}$} & 4.9 & .78 \\
\hline \multicolumn{3}{|c|}{$\begin{array}{l}\text { Frequently, I get discouraged. } \\
(\text { agree }=1 ; \text { disagree }=7)\end{array}$} & 5.1 & .90 \\
\hline \multicolumn{3}{|c|}{$\begin{array}{l}\text { A lot of people rub me the wrong way. } \\
\text { (disagree }=1 ; \text { agree }=7 \text { ) }\end{array}$} & 3.0 & .99 \\
\hline \multicolumn{3}{|c|}{$\begin{array}{l}\text { I am fairly sure of where my life is going. } \\
\text { (disagree }=1 \text {; agree }=7 \text { ) }\end{array}$} & 5.2 & .68 \\
\hline \multicolumn{3}{|c|}{$\begin{array}{l}\text { I have a good idea of what I want out of life. } \\
\text { (agree }=1 ; \text { disagree }=7 \text { ) }\end{array}$} & 3.3 & .80 \\
\hline
\end{tabular}

The students tested come from three universities located in California and Utah. Two of the three schools were private, religious institutions. The sample $(\mathrm{N}=169)$ consisted largely of undergraduate, nonsocial science majors. Over half were required to take the course, while others heard it was good, were simply curious, or just needed additional credit to graduate. The specific demographics of the students are reported in Table 2.

To determine student reaction to the course, two outcome variables were used: student satisfaction with the course (based on the satisfaction scale) and student performance (based on the student's actual grade in the course) ${ }^{2}$

\footnotetext{
${ }^{2}$ We realize that course grade is a rough measure of performance. However, we feel that the grade indicates a student's ability to manage ambiguity and create structure and learning out of uncertainty.
} 
Table 2

Student Characteristics

\begin{tabular}{|c|c|c|}
\hline College & 230 & $\mathbf{3}$ to $\mathbf{B}+$ \\
\hline Years in & llege & (junior) \\
\hline Months & rked & 32 \\
\hline Age & & 23.4 \\
\hline Expecte & rade in course & $46(B+)$ \\
\hline Sex: & Male & $75 \%$ \\
\hline & Female & $25^{\circ}$ \\
\hline Major: & Accounting & $24.5 \%$ \\
\hline & $\begin{array}{l}\text { Functional business (finance, marketing, } \\
\text { economics, organizational behavior) }\end{array}$ & 10.2 \\
\hline & General business & 37.1 \\
\hline & Social science & 11.4 \\
\hline & Physical science & 11.9 \\
\hline & $\begin{array}{c}\text { Other (fashion merchandising, } \\
\text { agricultural economics) }\end{array}$ & 4.2 \\
\hline
\end{tabular}

Student characteristics positively related to satisfaction were grade in the course and maturity. However, those with high GPAs experienced less satisfaction in the course. Evidently, those who perform well in other university courses are less satisfied with the ambiguous classroom setting. This may be indicative of the trends in education - moving back toward the traditional, structured class. In particular, accountants, fashion merchandising, and agricultural economics majors were less satisfied with the course. Perhaps students in these disciplines are more accustomed to the structured course, and when faced with an unstructured course on social issues, find themselves unable to deal with the ambiguity.

Table 3

Dependent Variable:

Student Satisfaction with the Course (seven point scale)

College GPA
Years in college
Months worked
Maturity
Age
Grade in course
Multiple R:
Sex: $\quad$ Male
$\quad$ Female

Major: $\quad$ Accounting
$\quad$ Functional business
General business
Social science
Physical science
Other

\begin{tabular}{|c|c|c|}
\hline Correlation & $\begin{array}{c}\text { BETA } \\
\text { (standardized) }\end{array}$ & $F$ \\
\hline-.111 & -.27 & $9.388 * *$ \\
\hline .159 & .096 & .816 \\
\hline .060 & -.078 & .553 \\
\hline .206 & .184 & $4.804^{* *}$ \\
\hline .132 & .034 & .073 \\
\hline .299 & .312 & $10.078^{* *}$ \\
\hline $.443^{*}$ & & \\
\hline
\end{tabular}

*Significant at .05

**Significant at .01

In assessing performance in the course, we found mixed results. As we anticipated, the expected grade in the course, the satisfaction with the course, and college GPA are good predictors of one's grade (see Table 4). However, maturity, months worked, year in school, and age are not significantly related to course grade. It

is interesting that those with a high GPA are less satisfied with the course, but still receive a high grade. Their lack of satisfaction does not affect their ability to produce, merely their ability to enjoy the experience. Students, regardless of the grade they received, have a good sense of their performance, as the expected grade is highly related to the actual grade. Evidently, students know when they are performing less than they should in an unstructured course. It is interesting that overall student GPA is the same for the unstructured course as for the overall GPA. Student fears of receiving a worse grade are unfounded.

\section{Table 4}

\section{Dependent Variable: Grade in Course (actual grade)}

\section{College GPA Years in college Months worked Maturity \\ Age \\ Expected grade in course Satisfaction with course Multiple R:

$\begin{array}{ll}\text { Sex: } & \text { Male } \\ & \text { Female } \\ \text { Major: } & \text { Accounting } \\ & \text { Functional business } \\ & \text { General business } \\ & \text { Social science } \\ & \text { Physical science } \\ & \text { Other }\end{array}$ \\ Overall \\ * Significant at .05 **Significant at .01}

\section{Conclusions}

As the pendulum swings from teaching structured to unstructured courses, we voice a need to stop and reevaluate our assumptions about teaching. If the purpose of our $O B$ courses is to teach names, facts, and functional issues, we can focus on structured techniques. However, if we want to encourage students who will not passively accept the values, behaviors, and norms of organizations, we may need to seriously consider the unstructured course.

The constraints inherent in an unstructured approach to teaching are considerable. One constraint is the sheer time and effort required to generate and monitor an open learning environment. We find such work requires approximately one-fourth more time than our efforts in the more traditional classroom design. Additional time is expended consulting students, searching out resource material, and meeting in 
small groups outside to facilitate action research. Much of the time is spent working through student fears of ambiguity and uncertainty. This requires counseling, or one-on-one time with students. To be prepared requires a high level of commitment by the professor and a broad range of conceptual preparation. To a certain extent, opening the flood gates to maximum diversity results in pedagogical overkill and may result in faculty paranoia because of the increased student demand.

A second constraint which often limits experimentation with lack of structure is that of one's professional peers. We find occasional sarcasm manifest at those "misfits" in the department who "don't work for a living" because the concept of an open classroom precludes a course syllabus. The unstructured approach elicits stronger reactions than normal teaching, which means there is a greater likelihood that students who are threatened or offended by such an approach complain to the department chairman or dean. The result for some faculty may be increased paranoia about their teaching, especially when student comments come back from the unprofessional or unprepared instructor. Universities are generally not known for their climate of experimentation and risk-taking, and intimidation from one's colleagues may reinforce a safe, conservative approach to teaching - one which is orderly, predictable, and will yield good student ratings.

And this brings us to a third limitation which may affect the availability of unstructured learning designs - the students themselves. Our experience shows that for students who have experience and maturity to deal with a rather abstract world, the unstructured class provides an opportunity to expand horizons and ask meaningful questions about self and organizations. These students, generally about 25 percent of the class, are satisfied and productive in the course.

We do not feel that this benefit is at the expense of the majority of students who may experience, initially, a more difficult time coping with the ambiguity. For those who have difficulty creating structure out of uncertainty, the course offers a rather safe place for this skill development. Even though this latter group may not derive the satisfaction the first group does, their learning does not appear to be significantly impaired. Our data are encouraging in that the expected grades and received grades are similar and that students' grades in the unstructured course parallel their overall college grades. The course allows the creative individual to be creative and the structured individual an opportunity to define parameters before facing the realities of an ambiguous world.

However, our experience is that the self-directed class becomes a painful learning process for many students. To what extent do we as faculty members have the right to subject "innocent" students to a highly ambiguous, conflictual process of self-examination? What are the ethics involved in creating an approach, as one of our students described it, that, "Instead of teacher-inflicted learning, what you've got is a student-inflicted approach. And it hurts!"? It is extremely seductive to respond to students' need for direction and feelings of dependency by stepping in as the Repository of Wisdom and give the answers they want. On the other hand, rather than reinforce that dependency, through unstructured learning we see a certain level of excitement and creativity immediately, and a more helpful autonomy and responsible approach to the world in the long run.

\section{References}

Bowen, D., "Experiential and Traditional Teaching of OB: A Dubious Distinction." EXCHANGE: The Organizational Behavior Teaching Journal, 5(3), 1980, 7-12.

McKelvey, B., and Sekarin, U., "Toward a Career-Based Theory of Job Involvement: A Study of Scientists and Engineers." Administrative Science Quarterly, 22, 1977, 281-305.

Wanous, J. P., "A New Look at Teaching versus Research." EXCHANGE: The Organizational Behavior Teaching Journal, 6(4), 1981, 9-13.

Woodworth, W., "A Self-Structured Approach to OB: Toward De-institutionalizing the Classroom.' EXCHANGE: The Organizational Behavior Teaching Journal, 4(3), 1979, 13-17. 